In Cres. Vol. $3 N^{\circ}$ 2: pp. 345-348, 2012

\title{
PARTICIPACIÓN POLÍTICA RESPONSABLE
}

\author{
RESPONSIBLE PARTICIPATION IN \\ POLITICAL LIFE
}

Graciela Pérez Morán ${ }^{(1)}$

\begin{abstract}
RESUMEN
El presente artículo analiza la participación política responsables desde la ISO 26000 Guía de Responsabilidad Social en el ámbito de las organizaciones, en tanto las organizaciones encausen en primer plano la ética como parte de la gestión y respaldo a las actividades que realiza a nivel interno como externo. El hecho de asumir la ética en sus decisiones va a requerir de la participación de todos los integrantes de la organización, lo cual debe ser expresado al momento de apoyar los procesos políticos públicos de manera transparente, respetando la norma y rindiendo cuentas de sus acciones, así como también evitando la influencia indebida, la manipulación, intimidación y la coerción, acciones que dañen el proceso político público.
\end{abstract}

Finalmente, se describen los conceptos y argumentos que definen la participación política responsable y la dinámica de intervención de las organizaciones con el entorno social, para promover el desarrollo de políticas públicas que conduzcan al crecimiento económico, político, social y cultural de la sociedad.

PALABRAS CLAVE: Ética, Organización, Participación política responsable.

La participación política responsable es el segundo asunto de la materia fundamental de Prácticas Justas de Operaciones de la norma Peruana ISO 26000 Guía de Responsabilidad Social, la cual se refiere a "apoyar procesos políticos y promover el desarrollo de políticas públicas que beneficien a la sociedad en general". ${ }^{1}$ Con ello proporciona fiabilidad y respeto al principio de legalidad que se rigen bajo las normas éticas, la rendición de cuentas y la transparencia en

* Recibido: 04 de mayo del 2012; aprobado: 25 de octubre del 2012.

(1) Magíster. Docente de la Universidad Católica Los Ángeles de Chimbote. 
los tratados, convenios y acuerdos que establece la organización con los Stakeholder, o grupo de interés.

El término de "participación" representa la acción dada en una sociedad cuando es parte y comparte con otras personas algún asunto e interés. Esta actuación es posible cuando por lo menos existe más de una persona. León (2007 citado en Gonzales 1990²) señala que la participación "alude a la forma de intervención social que le permite a los individuos reconocerse como actores que, al compartir una situación determinada, tienen la oportunidad de identificarse a partir de intereses, expectativas y demandas comunes (...)". Es decir, la participación no es aislada o delimitada en un contexto sino, por el contrario, forma parte de la sociedad, es compartida, su accionar requiere de la participación conjunta de las organizaciones, sociedad civil y comunidad en general, que conlleven al crecimiento económico, político, social y cultural de la sociedad.

Por su parte, el Pontificio Consejo Justicia y Paz (2005) define que la consecuencia de la subsidiariedad "es la participación que expresa, esencialmente, en una serie de actividades mediante las cuales el ciudadano, como individuo o asociado a otros, directamente o por medio de los propios representantes, contribuyen a la vida cultural, económica, política y social de la comunidad civil a la que pertenece.". ${ }^{3}$ Entendiéndose de este modo, la organización debe colaborar con los procesos políticos públicos de la sociedad que conduzcan al compromiso personal y social. Pero esta contribución debe ser generosa y caritativa, evitando la influencia indebida que busca el beneficio propio; debe garantizar a los ciudadanos buena salud, educación y trabajo.

La participación no solo se da en condiciones informales, sino también formal. La relación es asimétrica y sinérgica; establece la distribución de roles y el logro de los objetivos en bien de la sociedad y de la organización; permite que cada individuo u organización aporte en mayor o menor medida al desarrollo de las políticas públicas, ya que, los resultados enriquecen, benefician y fortalecen al colectivo del capital social. ${ }^{4}$

Dicho de otro modo, la participación se refiere a aquella intervención donde el ciudadano se desarrolla como persona, es escuchado, aporta, se involucra y autogestiona proyectos con la población. Sin embargo, cuando la participación solamente se da como gesto de recibir y sin intervenir, se corre el riesgo de caer en el asistencialismo de ofrecer apoyo sin antes haber incorporado, validado y compatibilizado los verdaderos intereses y necesidades de la población. Esto no quiere decir que dejemos de lado el asistencialismo, sino por el contrario, utilizarlo en situaciones de desastres, emergencia y ayuda humanita- 
ria y enseñar a pescar; de este modo, no sigan siendo dependiente sino más bien con la ayuda de todas las organizaciones puedan salir de la pobreza. Ante esto, es necesario orientar los procesos políticos hacia un crecimiento sostenido en la comunidad.

Llevando la participación al ámbito político, el Diccionario de Ciencias Políticas, la define como semejante a la participación del ciudadano en el proceso político; es el ejercicio como una forma de conducta social que abarca el ejercicio de los derechos garantizados por la ley y la constitución (derecho de sufragio, reunión y a la manifestación pública) y a la conducta informal (conversaciones políticas con vecinos, amigos o compañeros) o procesos mentales (interés político). ${ }^{5}$

Por su parte, Fernández define la participación política como "el conjunto de actividades, interacciones, comportamientos, acciones y actitudes que se dan al interior de una sociedad (...)" ${ }^{\prime 6}$, lo que implica que este conjunto de actividades no deben estar aisladas del campo de las relaciones sistémicas globales pertinentes, sino que busque incluir impactos que beneficien a la comunidad en general y al medio ambiente, su funcionalidad está articulado a procesos políticos, económicos, social, cultural y de ciudadanía.

Sabucedo también considera la participación política como "cualquier tipo de acción realizada por un individuo o grupo con la finalidad de incidir en una u otra medida en los asuntos públicos. (...)". ${ }^{7}$ Es decir, la participación política moviliza a las organizaciones e impulsa a trabajar con la comunidad organizada en la solución de los problemas públicos y apoyar las políticas públicas activas descentralizadoras que se orienten hacia una visión de futuro, de sostenibilidad y no solo a un cálculo político.

La ISO 26000 señala que el apoyo que ofrece la organización a los procesos políticos públicos deben ser respetando los espacios y situaciones de cada organización, evitando el control y la influencia política, incidiendo en la transparencia para erradicar el clientelismo y la corrupción, que no suponga una amenaza sino por el contrario ser un soporte de funcional de las políticas públicas.

Por otro lado, ha sido clave la incorporación del término responsable en las organizaciones, pues busca incorporar acciones éticas y valores en los procesos de gestión. Ser responsable deviene de otros valores, como respeto y consideración, difíciles de alcanzar pero no imposible. El cumplimiento va a depender del compromiso y la capacidad de madurez que tenga la organización para aceptar a los trabajadores y empleados con sus deberes y derechos y al grupo de interés o stakeholders como parte de ellos. 
La Real Academia señala que responsable es "la persona que cumple sus obligaciones o pone cuidado y atención en lo que se hace o decide". Conduce a reflexionar sobre la convivencia habitual y rutinaria que la organización realiza y que requiere cumplir procesos orientados hacia la cultura de la prevención y la transparencia, respeto a las normas éticas, rendición de cuentas, respeto a la ecología, a la economía y al ámbito social, por cuanto, la organización es responsable en la medida que reconoce que las consecuencias de sus acciones están afectando a nuestras generaciones futuras.

Finalmente, se deduce que la participación política responsable es la acción ética que ejerce una organización para apoyar el proceso político en el marco no de una ética de las buenas intenciones, contribuyo con mi comunidad porque tengo buenas intenciones de quedar bien, ganar aplausos o recibir votos en las elecciones, sino más bien, porque tenemos sed de ética; por ello los aportes y contribuciones deben orientarse a fortalecer el capital social a través de la confianza, la cooperación entre las personas, organizaciones y sociedad en su conjunto de manera desinteresada, evitando la corrupción, manipulación, intimidación y coerción, espacios que deterioran el proceso político.

En pocas palabras, la integración de la participación política responsable en las organizaciones, involucra al todo con sus partes, porque la organización no es una isla en la sociedad, sino, por el contrario, es un ciudadano más, forma parte de un contexto local y global y se convierte en parte del crecimiento humano y del desarrollo social. De allí que pongo al debate que la organización debe apoyar los procesos políticos con visión de futuro que conduzca a la sostenibilidad y a promover el desarrollo de políticas que beneficien a la sociedad en general.

\section{NOTAS}

1 INDECOPI (2011) Norma Técnica Peruana. ISO 26000. Guía de Responsabilidad Social. R.00412010/CNB-INDECOPI, publicada el 29-01-2011.

2 LEÓN C. (2007) Empoderamiento como indicador del desarrollo. Universidad Autónoma de Manizales. Colombia, 2007.

3 Pontificio Consejo “Justicia y PAZ”. (2005). Compendio de la Doctrina Social de la Iglesia. Editorial Paulinas. Marzo, 2009.

4 Masgo W. (2012). Participación Política y Ciudadanía. Curso V. Lección 1. Dirección de Participación Ciudadana. Lima Perú. Disponible en: http://www.congreso.gob.pe/participa/ cursos/textos/CURSO_V_LECCION_1.pdf.

$5 \operatorname{Idem}(4)$

6 FERNÁNDEZ (1999) Algunas aproximaciones a la participación política. Revista Reflexión Política. Año $N^{\circ} 1$. Colombia, 1990. Disponible en http://redalyc.uaemex.mx/pdf/110/11010112.pdf.

7 Ídem 4. 